\title{
Democratización y debate público en Querétaro: Discurso y visibilidad en la prensa a 20 años de la alternancia
}

\section{Democratization and public debate in Querétaro: Speech and visibility in the press 20 years after the alternation}

\author{
Dr. Gabriel Alfonso Corral-Velázquez \\ Universidad Autónoma de Querétaro. México. \\ corral@uaq.mx \\ https://orcid.org/0000-0002-6885-4913

\begin{abstract}
Resumen
Este trabajo ofrece una discusión sobre el debate público en el proceso de democratización en México. El objeto de estudio de este trabajo en concreto es debatir el acceso y visibilidad de los actores sociales en la prensa en perspectiva a veinte años de la alternancia electoral.

El estudio se realizó en una metodología mixta que articula elementos del análisis de contenido y de discurso de notas y opiniones publicadas en la prensa queretana lo cual permitirá comprender la debilidad o no de la esfera pública de Querétaro.
\end{abstract}

\begin{abstract}
This paper discusses the public debate in the democratization process in Mexico. The object of study is to debate about the access and visibility of the social actors in the press from a historical perspective, twenty years after the electoral alternation occurred.

A mixed methodology that merges elements of content and discourse analysis was applied to notes and opinions published by the Queretaro local press. This amalgamation enables the questioning of the weaknesses of the public sphere of Querétaro.
\end{abstract}

Palabras clave: Esfera Pública; Democratización; Visibilidad; Discurso.

Keywords: Public Sphere; Democratization; Visibility; Discourse. 


\section{Introducción}

Resulta imperativo hacer un balance a veinte años de la alternancia electoral. Esto es, reconocer si la brecha entre promesas y realidad sigue inmutable en la rutina sexenal de nuestro país: desde aquel lema de Democracia y Justicia Social que usara Miguel Alemán en su campaña presidencial de 1946, pasando por la Renovación Moral de Miguel de la Madrid en 1982 o el Cambio prometido por Vicente Fox Quezada en las elecciones del año 2000; se puede decir no tan solo que la gran cantidad de términos relacionados con el tema es norma en México sino que la configuración de las sociedades verdaderamente democráticas no se produce a base de dogmatismo conceptual sino de pruebas reales. Medir la satisfacción democrática de los ciudadanos mexicanos es algo que hacen regularmente encuestas como el Latinobarómetro o la Encuesta Nacional de Cultura Política y Participación con resultados cuando menos decepcionantes.

Si la democracia representativa iba a ser el parteaguas entre la cultura autoritaria, vertical y arbitraria del poder consuetudinario en México y las nuevas formas de participación popular lo menos que puede decirse es que las ilusiones nunca se concretaron realmente. El concepto de esfera pública y su configuración en Querétaro permiten adentrarnos en la posibilidad de la interacción y la comunicación no coactiva entre actores sociales es la base de esta idea motriz de la democracia liberal, no es ocioso preguntarse si en Querétaro los factores reales del poder clase empresarial y administración pública- abrieron los canales de comunicación con la sociedad civil para que las expresiones de inconformidad, proposición o transparencia tuvieran su lugar en el proceso de toma de decisiones que afecta al desarrollo social, económico y cultural de Querétaro. El abordaje analítico este documento se pueden resumir en la siguiente pregunta: ¿Se consolidó el debate público en Querétaro tras la transición democrática y la alternancia política o la discusión pública permanece mostrando que la agenda del poder se impone por encima de la sociedad civil?

De acuerdo con la Encuesta Nacional de Cultura Política y Prácticas Ciudadanas 2012', seis de cada diez ciudadanos ven en la democracia su sistema de gobierno preferido. Sin embargo, 65 por ciento de los encuestados manifestaron conocer poco sobre este sistema político o tienen poco interés sobre asuntos vinculados a la política. En un contexto de presunta democratizaciónii, como el que se vive México desde hace ya dos décadas, parece contradictorio que distintos sectores de la sociedad muestren tal alejamiento de la política mientras señalen a la democracia como su forma de gobierno preferida; un asunto que llama la atención toda vez que uno de los supuestos contemplados en todo proceso de democratización es la participación de todos los sectores sociales en la discusión de los asuntos públicos garantizando el acceso a la información de todos aquellos aspectos comunes a la sociedad civil.

La democratización es inconcebible sin los medios de comunicación cuya función de crítica es esencial para evitar, justamente, el abuso de poder. Esta concepción ideal del cuarto poder, ampliamente cuestionada en las teorías de la comunicación, contrasta con la realidad social: ni espectadores críticos ni medios independientes son mayoría en México.

\section{La participación política y el debate público}

El marco mediático impone un cambio normativo, la sociedad de masas o sociedad de los medios, la cual desborda el ámbito de interacción de la comunicación política y el debate "racional" que se verificaba en un espacio ceñido por el tiempo y el territorio, al de la mediatización de la vida pública, donde los dispositivos son tecnológicos (medios) e institucionales (el Estado y sus instituciones), y el público no está limitado al cuerpo de una región o nación. Los públicos modernos, en oposición a las comunidades tradicionales, son conjuntos de personas que, aún sin 
estar en interacción persistente, incluso sin forma alguna de presencia mutua, están sometidas a los mismos estímulos sociales (Andrade, 2009: 93).

Los medios de comunicación serían, pues, el núcleo rector del nuevo espacio público pero la venta de información al público no construye una comunidad de ciudadanos críticos, sino que genera una representación mediada de la realidad social. Esto describe una idea intervenida por elementos cognitivos tanto como por condiciones de producción de cada medio. De esta manera se describe cómo el discurso está impregnado de imaginario político, lo que supone aspectos de la realidad y la fantasía de esa comunidad (Andrade, 2009).

En la esfera pública, los actores toman posición en el debate a partir de su acción discursiva, que se manifiesta en prácticas concretas. La acción del discurso no refiere solamente al ejercicio lingüístico, sino que se hace patente a partir de prácticas de referencia. Por lo tanto, a través de él se ponen de manifiesto las relaciones en la esfera pública, el proceso de democratización y prácticas, tanto emergentes como arraigadas, de una cultura política en la esfera pública. En este sentido, la cultura política es representada por sistemas de valores, representaciones simbólicas e imaginarios colectivos, que se ponen de manifiesto en los discursos y prácticas observados en la esfera pública (Almond and Verba, 2001).

Con los referentes estructurales de la cultura participativa y los de los sujetos se pueden establecer articulaciones en al menos dos sentidos. Por un lado, la referencia a un entorno global que permite una participación más activa de los usuarios en los bienes de consumo mediático que los involucra y los hace partícipes de la gestión y distribución de estos y por otro los propios referentes de los sujetos que los incluye en grupos de referencia. Esto hace relevante el análisis en virtud de conocer y analizar estas comunidades que han permitido formas innovadoras de consumo y producción de significados compartidos con relación a productos mediáticos y la relación que ésta adquiere en su vida cotidiana, lo que constituiría la esfera pública, epicentro del debate público.

Recuperar el concepto de esfera pública desde la mirada de Habermas (1981) abre la posibilidad de analizar los contrastes que existen en los diversos niveles de acceso a los espacios de debate. En estos planteamientos la esfera pública es el espacio en donde lo público y lo privado se juntan e interactúan. Tiene relación con las múltiples demandas provenientes de distintos dominios de la sociedad civil así como con las decisiones estatales. Tanto la sociedad civil como las autoridades se visibilizan e interactúan en la esfera pública de diversas maneras, para cuestionar y presentar argumentos, criticarse, explicarse, justificarse y legitimar sus actos, sus acciones e incluso sus omisiones.

Se pretende articular, por un lado, los estudios, los procesos de democratización que recuperan el concepto de esfera pública y han abierto la puerta para entender la interacción de grupos, asociaciones y movimientos en los mismos procesos democráticos. Por otra parte, pretende comprender, desde el marco comunicativo, la relación argumentativa y discursiva de los distintos grupos sociales con la organización política, el Estado y el mercado. Los argumentos manifiestan la posición de los sujetos y la forma en que estos actores sociales son visibilizados (o no) en la esfera pública. Sostengo que la configuración de la esfera pública se construye a partir de la visibilización de los sujetos en sus discursos y prácticas.

Señala Thompson (1998) que tras el surgimiento de las sociedades modernas, origen también de la democracia de masas, hubo una serie de transformaciones en la producción y circulación de las formas simbólicas definidas como "acciones, objetos y expresiones significativas de diversos tipos" (Thompson, 1993, p. 203). La esfera pública sería justamente este espacio en el cual se visibilizan actores y se socializan estas formas simbólicas. Cabe señalar que la esfera pública refiere objetos y lugares, por lo que tiene, ciertamente, un valor simbólico. En este sentido, el concepto es tan material como simbólico. En ella se manifiestan, un amplio campo de fenómenos 
significativos, acciones, rituales y discursos. La esfera pública es el espacio de producción y circulación de formas simbólicas relacionadas con ciertos contextos y procesos -históricamente específicos y socialmente estructurados- gracias a los cuales se producen, transmiten y reciben tales formas simbólicas.

Es por ello, que en el análisis sociológico de la democratización de la esfera pública resulta un elemento relevante para este trabajo. Este espacio de asociación libre y acción discursiva, cuyo sentido deriva de la función crítica y la capacidad de generar opinión pública (Habermas, 1981) tiene su expresión en la prensa libre, el lugar donde se materializa la esfera pública. Analizarla es enriquecer nuestro estudio sobre las contradicciones existentes en el proceso de democratización a nivel institucional y los espacios reales de debate en torno a asuntos de interés público.

Uno de los problemas acotados es que, en el caso mexicano, el acceso al debate público se reduce. Como ya se ha dicho, democratización implica incorporación, a la esfera pública, de prácticas ligadas a la democracia. Una de ellas es el acceso igualitario al debate público, y en caso de no darse tales condiciones deben analizarse las implicaciones políticas que tiene este diferenciado acceso a la visibilidad pública, que genera una obvia desigualdad entre los actores sociales encargados de producir y reproducir las formas simbólicas configuradoras de la cultura política.

Por medio del análisis de prensa se pretende estudiar cómo se reproducen determinados discursos en torno a asuntos de interés colectivo, qué actores participan en él una vez son visibilizados y reconocidos como voces "autorizadas" para hablar sobre determinados asuntos y cómo construyen sus argumentos estos sujetos mientras se involucran en un espacio de discusión que pudiéramos llamar democrática.

Es posible observar, en la esfera pública, estas formas simbólicas que permiten el arraigo de prácticas particulares de concebir la política (Thompson, 1998). Esta materialización de formas simbólicas en la esfera pública se puede dividir en tres segmentos:

1) La visibilidad de los actores que participan en torno a asuntos públicos.

2) La forma en que se presentan argumentos, los cuales permiten la producción y apropiación de estos.

3) La posibilidad de crear y sostener legítimamente una creencia a partir del uso político del poder simbólico que representa cada uno de los actores visibles.

Realizar un abordaje de las prácticas culturales a partir del planteamiento normativo o ideal de esfera pública es uno de los motores de este documento. El desajuste entre la esfera pública pura y la democracia de mercado realmente existente forma parte de las discusiones sobre el proceso de modernización, una de cuyas variantes incluye los procesos de democratización.

Este análisis plantea si esta paradoja también se dio en el estado de Querétaro analizando la relación entre prensa, sociedad civil y gobierno. Se parte de la idea de que todo proceso de democratización tiene matices particulares. No hay modelo ideal. En cada transición de los regímenes autoritarios a la democracia representativa, existen intereses políticos, simbólicos y materiales particulares que juegan sus cartas para controlar la espiral de cambios. También para el caso queretano, este análisis arroja luz sobre las prácticas sociales que ponen de manifiesto la desigualdad de recursos y de acceso al debate público entre actores sociales y políticos, así como las dificultades culturales, legales e institucionales para poner en marcha nuevas formas de participación democrática en asuntos de interés colectivo.

Para Avritzer (2002), el abordaje sociológico de la democratización, eje principal de este trabajo, debe hacerse a partir de la incorporación de conceptos clave como sociedad civil y esfera pública. La democratización es un proceso en permanente construcción y nunca enteramente acabado. 
Durante estos mismos procesos de democratización, se generan nuevas tensiones que buscan expresión y visibilidad en la esfera pública, aunque en algunos casos permanecen ausentes o latentes. Junto a Sousa, Avritzer asume una línea crítica ante el modelo hegemónico -la democracia representativa elitista- que se impuso en todo el mundo tras la caída del bloque soviético (Avritzer y Sousa, 2003).

Su mirada no se enfoca en las formas y procedimientos de la democracia institucional sino en la configuración de la esfera pública como el lugar donde los actores y sus intereses son representados o invisibilizados. Observar/detectar la presencia o ausencia de ciertas voces en la esfera pública es una señal que permite preguntarse sobre las formas de diálogo entre actores sociales y su existencia real más allá de los discursos del poder.

Es decir, sólo ciertos sectores vinculados al poder político y económico definen los términos del debate en la esfera pública de Querétaro y para comprobar esta idea es necesario "analizar la forma en que se expone, en la esfera pública, un asunto de interés comunitario a cargo del gobierno estatal; examinar la labor periodística de diarios locales respecto de dicho tema, y ofrecer un análisis general sobre la construcción colectiva de decisiones cruciales en la vida comunitaria que este proceso representa" (Acosta et al, 2014, pp. 134 - 135).

\section{La Esfera Pública y el contexto político en Querétaro}

Para entender esta configuración de la esfera pública, dicho a la manera de Elías (1999), es necesario ir más allá de lo institucional y observarla en el entorno de las relaciones sociales y de la cultura política. El discurso ofrece la posibilidad de conocer de voz de los actores las tensiones entre el entorno institucional democratizado y la propia esfera pública. Es lícito plantearse una cuestión central: ¿Es compatible la conceptualización de la esfera pública desde el Estado mexicano con prácticas autoritarias que desarrolla este mismo Estado? De tal forma que, suponiendo que el caso mexicano, con sus particularidades, se analice como modelo de democratización exitosa, ¿qué características tiene la esfera pública surgida del cambio de modelo político?

No hay mejor forma de saber las reales características de la esfera pública queretana que analizar el discurso en la prensa, pues es el dispositivo empírico que congrega los actores, las posiciones y los argumentos visibles en la vida pública del estado. Igual que sus silencios u omisiones dejan en claro quién debería tener su lugar en ella y por qué no lo tiene.

La propuesta del estudio de la prensa, así como las relaciones que en torno a ella se establecen, es también analizar el carácter social de la esfera pública ya que en la prensa convergen los distintos actores en un proceso democrático. Así, se parte de entender la esfera pública, hoy, como el espacio audiovisual asociado a los medios de comunicación (electrónicos, impresos) y el ámbito de sus interacciones sociales (asociaciones sindicales, civiles, movimientos sociales). Mediante la prensa, en la esfera pública se van a conectar dos discursos: el privado y el público (Habermas, 1981). Los debates entretejidos de ideología, lucha por la hegemonía y propaganda revisten los intereses privados en la máscara del interés público. De ahí el planteamiento común de las tecnologías de comunicación (TIC) como parte de un proyecto de democratización de las sociedades es decir, en la creación de una esfera pública incluyente (Subirats, 2012). Sin embargo, se plantea en este trabajo que la democratización de los medios es una asignatura pendiente que ha pasado de la esfera pública a la legislación gubernamental. La prensa termina por convertirse es el espacio natural de debate de los asuntos públicos, ya que la visibilidad de los actores y los posicionamientos pasan necesariamente por los medios.

En Querétaro, a pesar de las constantes acusaciones sobre su cercanía con los poderes fácticos del Estado, los periódicos han sido parte sustancial de los procesos políticos que han tenido lugar 
en los últimos años. Reflejo del panorama nacional del régimen posrevolucionario, Querétaro consolidó el modelo de subordinación de la prensa al poder político. La prensa del estado es el medio más antiguo de información y opinión. Hasta 2002 dos medios fueron dueños, por medio de una diversidad de prácticas, de la producción de información: el Diario de Querétaro y el Noticias, quienes se involucraron estrechamente con las élites del poder y, en particular, con el partido gobernante, el PRI.

Desde los noventa, sin embargo, existieron intentos de diversificación de este medio pero también fue la década del despegue de los informativos radiofónicos (Espino, 2003). La radio pasó a ser el medio de mayor alcance en el entorno social de Querétaro relegando a las dos filiales de las televisoras nacionales (Noticieros Televisa Querétaro y Hechos Querétaro) y rebasando, en impacto y credibilidad, a la prensa. Las características de agilidad y rapidez del propio medio permitieron a las primeras emisoras establecerse como el referente informativo local.

Sin embargo, históricamente la agenda informativa la establece la prensa. Las radios y escasas televisoras locales reproducen los periódicos a partir de las síntesis informativas que privilegiadamente se remiten a los diarios. Las producciones audiovisuales dedican sus esfuerzos, principalmente, a la venta de espacios publicitarios y al entretenimiento. Así, a pesar de la creciente oferta de medios se observa que los espacios mediáticos no reflejan la pluralidad de los actores sociales.

En este trabajo, el discurso es entendido como una práctica social que se realiza dentro de entornos particulares. Razón por la cual remite no sólo a situaciones y roles intersubjetivos sino también a posiciones concretas en la trama de las relaciones sociales. Al mencionar la importancia del concepto de configuración, la intención es ubicar y visibilizar estas prácticas que sostienen el cuerpo del discurso y el lugar que ocupan los actores en los equilibrios fluctuantes que genera la interacción social.

Históricamente, el caso de la esfera pública de Querétaro resalta por la falta de conflictos, incluso en los momentos de transición y alternancia política que se dieron en la década de 1990. Las voces disidentes han sido, por norma, escasas o poco visibles. Se sostiene que tanto la esfera pública de Querétaro como la propia cultura políticaiii dominante están estrechamente ligadas al desarrollo económico-industrial de la región. La capacidad de adaptación de las élites tradicionales a los cambios de coyuntura habidos en el entorno económico y político, sobre todo a partir de los años cuarenta, tuvo como resultado la transformación de los hacendados en empresarios (Nieto, 2000, p. 105) y la cooptación de cuadros políticos, intelectuales y personal migrante que fueron incorporándose, en forma armónica, al poder empresarial y político de Querétaro.

Para Morales (1998) existieron tensiones y diferencias por el control político del Estado, en especial, cuando en la primera mitad del siglo XX los hacendados tuvieron que lidiar con el colapso del latifundismo y la nueva política de sustitución de importaciones que derivó en el acelerado proceso de industrialización, generando una nueva clase de empresarios-políticos que desafiaron el ancestral poder de los ganaderos (Morales, 1998).

Sucedió, pues, que en un período no mayor a cuatro décadas, Querétaro pasó de ser una entidad eminentemente rural, enraizada en actividades agropecuarias, a un estado urbano e industrializado, basado en los sectores secundario y terciario, sea industria, comercio o servicios. Señala González (2013) que esta intensa actividad industrial modificó la estructura poblacional y comenzó a atraer a trabajadores migrantes a los centros urbanos de Querétaro. La demografía, estable desde el virreinato hasta 1940, cambió de raíz. El anémico crecimiento poblacional se aceleró a partir del último tercio del siglo XX provocando un aumento considerable en la población queretana. 
Evento poblacional al cual se sumaron dos tendencias: la desconcentración de la planta industrial de la zona metropolitana de la Ciudad de México y los sismos del valle de México en 1985, que provocaron desplazamientos masivos, complementados por el constante flujo migratorio de trabajadores del interior del país. En 1980 la población residente en la ciudad era de apenas 215,976 personas. Para el año 2000 , la cifra rebasa el medio millón de habitantes: 536,463 en totaliv. En dos décadas, Querétaro duplicó su población. Tendencia migratoria que sigue activa hoy en día.

En referencia a la vida política, la prolongada reforma del Estado mexicano promovida durante los años ochenta y noventa, impactó en todas las instancias de gobierno tras la lenta desintegración del partido-estado que fue el PRI. En esta progresiva pérdida de la verticalidad autoritaria, las entidades federativas asumieron sus propios procesos de modernización y democratización. El caso de Querétaro es ejemplar en ese sentido. A partir de 1997 se dio la alternancia electoral como consecuencia de las reformas constitucionales que dieron pie al cambio político, cuyo mayor éxito se presenta con la llegada del Partido de la Revolución Democrática a la jefatura del Gobierno del Distrito Federal el mismo año que Querétaro convertía a Acción Nacional en el primer partido del estado, resultado que marcó una etapa transicional democrática anhelada por décadas.

Desde aquel entonces, el estado cuenta con dos alternancias electorales en la gubernatura estatal así como numerosos cambios en los gobiernos municipales y en la misma legislatura. Siguiendo la literatura clásica sobre transiciones -un Estado se democratiza a partir del marco institucional- se podría considerar que Querétaro vive un proceso de democratización sostenido a partir de 1997 ya que cuenta con 3 alternancias electorales en 2009 y 2015 las más recientes. Con la tercera alternancia en Querétaro se puede considerar que existe una "normalidad" electoral; sin embargo, en términos de cultura política los cambios son poco perceptibles en el ámbito público.

Desde el marco normativo esta entidad federativa cumple a carta cabal con el canon democrático. Pero fuera de la politología estricta, y abordando la investigación desde las prácticas sociales y el mismo acceso al debate público, muchos son los indicios que las elecciones y la alternancia en los gobiernos no convierten a Querétaro en una entidad democrática con una robusta esfera pública. Es decir, no existe una sana y real correlación entre los procesos de democratización institucional y la democratización de los espacios sociales.

En el contexto histórico se señalan algunas posibles causas por las que este nuevo marco institucional haya dejado intacta la estructura de poder en el estado. Puede que el consenso de las élites político-empresariales sea más profundo y duradero que los cambios políticos habidos en la superficie del poder político. Aunque los grandes teóricos de la escuela italiana, como Mosca - Pareto, dejaron en claro que el poder es siempre cosa de minorías, no puede extirparse del debate público una cuestión tan actual como la calidad real de una democracia concebida desde arriba: "Si bien una élite unificada puede asegurar una democracia estable, su predominio dice directa relación con el ejercicio del poder y la calidad de la representación, porque el peso que adquiera una minoría entra inevitablemente en tensión con los principios de un régimen democrático" (Espinoza, 2010, p. 253).

El sentido es mostrar que, pese a las reformas de los últimos veinte años, existen "continuidades" de fondo en las élites político-empresariales que se pueden ver en la deficiente esfera pública, la forma en que los sujetos exteriorizan valores, expectativas y aprendizajes que luego se hacen patentes en sus prácticas sociales. Su estudio induce a pensar que la esfera pública de Querétaro permanece cerrada a determinados actores sociales y políticos que no comulgan con el poder. Como consecuencia, su presencia se ve disminuida. Lejos de los reflectores, sin acceso a los medios, la acción discursiva sobre la cual se construye la opinión pública queda acotada a unos pocos y seleccionados actores que definen las pautas del discurso y el debate. 
Es por ello por lo que urge elaborar un análisis de la cultura política democrática (ideal) y la cultura política real (poderes fácticos). Sólo el análisis de esta paradoja puede dar cuenta de las diferencias que existen entre los distintos grupos sociales, cuyo corolario son ciertas y determinantes estructuras que abren o cierran el acceso a la esfera pública en los medios de comunicación, concretamente de la prensa y loa medios electrónicos. Mostrar cómo conviven mecanismos, prácticas y valores propios de una cultura política autoritaria con normas y cambios institucionales de un estado democrático-formal. Contradicción profunda que se expresa en la esfera pública, espacio donde se llevan a cabo estas interacciones, lugar donde se concretizan y se condensan los intercambios comunicativos de la vida social y constructo que permite analizar estas prácticas a partir del discurso de los actores.

Por ello, estudiar las tensiones que se generan entre un espacio institucional abierto e igualitario y la esfera pública dominada por una sociedad política jerárquica, vertical y cerrada, reflejo de una ancestral cultura política que no favorece la democratización de sus espacios de debate.

La relación entre los actores sociales (clase política, empresarios, periodistas, sociedad civil organizada, sociedad en general) y los temas de interés público definen aquello que se entiende por esfera pública, espacio en el que se producen y reproducen formas simbólicas, es decir discursos y prácticas.

La esfera pública de Querétaro no cuenta con muchos ejemplos respecto a situaciones que hayan generado mayor sobre salto en las discusiones en torno a lo público. Los movimientos sociales han sido más bien de coyuntura y las representaciones en algún momento estuvieron cooptadas por el partido en el gobierno o por las élites económicas industriales o hacendarias.

Con el proceso de democratización institucional se abrieron espacios a otros sectores. Los cuales, en algún sentido, han sido utilizados para canalizar demandas o en su caso para protestar por decisiones tomadas por las autoridades gubernamentales y que a sentir de los afectados vulneraba algunos derechos.

En este trabajo se lleva a cabo un análisis de discurso a través de categorías que incluye los siguientes ejes: esfera pública como espacio de debate, actores sociales, visibilidad y discursos (o argumentos) que hacen posible su presencia y visibilidad en la esfera pública. Todos estos ejes son vistos a través de esquemas de análisis que permiten reconocer los niveles de visibilidad y constancia en los espacios adjudicados en los medios de comunicación.

La estrategia de análisis tiene un acercamiento mixto, toda vez que para construir los datos a estudiar se desarrolla un ejercicio de correlaciones de tipo cuantitativo a partir de las variables propuestas seguido de un ejercicio de análisis más interpretativo. Con este doble abordaje, se busca acotar los elementos que puedan evidenciar las contradicciones planteadas en torno a las condiciones de acceso a la esfera pública de Querétaro.

Para dar cuenta de ello se ha construido un análisis de análisis discursivo híbrido, cualitativo tanto como cuantitativo, aplicados a una selección de notas periodísticas que presentaron en los principales diarios de la ciudad de Querétaro.

\section{Discurso y Esfera Pública}

Para llevar a cabo el estudio se recupera la idea del discurso como práctica social desde Van Dijk (2006). Para el autor, el discurso como práctica social se entiende como el conjunto de interacciones comunicativas propias de un grupo o sociedad, el contexto, la adopción del discurso como práctica social de los integrantes de un grupo y su categorización, la secuencialidad y funcionalidad de los niveles y dimensiones del discurso y la cognición social. El discurso puede establecer la posición de los actores frente a situaciones sociales, plantea significaciones, 
interpretaciones del entorno. Este abordaje permite enfocarlo en el sentido formal, que refiere a lo que dice y a su contexto es decir acción e interacción.

En la esfera pública los actores toman posición en el debate a partir de su acción discursiva, que se manifiesta en prácticas concretas. Entendido de esta forma, la acción del discurso no refiere solamente al ejercicio lingüístico, sino que se hace patente en las prácticas de referencia. Es relevante puesto que permite analizar en conjunto discurso y prácticas en la esfera pública relacionadas con la democratización. Con esto se pretende poner de manifiesto si existe relación entre los debates en la esfera pública y el proceso de democratización o si prevalecen las prácticas arraigadas en las prácticas de una cultura política autoritaria en la esfera pública.

Hay que señalar que el discurso como práctica social y los sujetos que producen las formas discursivas deben estar inscritos dentro de un proceso social claro y que permita comprender la relación que existe. Por ello el discurso se analizará a partir de posiciones y subjetividades. En el discurso manifiesta el actor manifiesta su posición respecto del tema y hace énfasis en las referencias a las que se encuentra afiliado. Las posiciones refieren al lugar que ocupa dentro de los actores involucrados en la esfera pública. Esto quiere decir que el actor al formar parte del debate su discurso lo identifica y a partir de éste toma posicionamiento. En este sentido se retoman para el análisis tres aspectos que son importantes:

a) El discurso debe inscribirse dentro de un proceso social. Es un ejercicio discursivo que asume una posición determinada dentro del entorno en el cual es producido y por ende hace referencia a aspectos sociales, culturales e ideológicos.

b) Todo discurso remite de manera implícita o explícita a un sistema de relaciones y representaciones sociales preexistentes. Los cuales siempre hacen referencia a una escala de valores dominantes o subalternos en constante lucha y cuya articulación compleja y contradictoria definen la conformación de una sociedad.

c) El discurso se presenta como una práctica ritual, atada a aspectos culturales dentro de un marco social de significación.

Este enfoque, para el trabajo que se presenta permite un acercamiento para la explicación de los fenómenos políticos. Como señala Gutiérrez (2003) Los discursos no son "algo que refleja la realidad, tal y como sucede, sino que más bien construyen representaciones de esta. De igual forma ayudan a construir representaciones de las prácticas sociales, de los actores que intervienen en estas y de las relaciones que se establecen entre ellos" (Gutiérrez, 2003).

De esta manera, el discurso como practica social incide en el mantenimiento, refuerzo e incluso en la transformación de la identidad, del orden y de la cohesión social (Gutiérrez, 2003: 98). Es importante, en este sentido, destacar que en los discursos se deben considerar los factores de tensión y desigualdad que se producen entre los diferentes fragmentos enunciativos que se incorporan al discurso principal. Esto es, no todas las voces tienen la misma importancia o trascendencia social, pues algunas pueden ser reproducidas o introducidas a maneras de citas de autoridad, al mismo tiempo que otras pueden no ser consideradas relevantes e incluso pueden ser excluidas.

En este sentido, el discurso y sus usuarios, al ser miembros de comunidades, organizaciones, grupos e instituciones, hablan, escriben y perciben la realidad social desde determinadas posiciones; a partir de esta posición es como se asumen valores, se identifican, rechazan o cuestionan ideas de otros usuarios.

La complejidad de esto implica en que de alguna forma al momento de estructurar un sentido de discurso respecto de un tema en particular se incorporan, interactúan y están en constante "tensión" los hablantes. Esto quiere decir que los discursos deben concebirse como heterogéneos, los cuales se diversifican según las situaciones concretas donde se produce. 
El discurso, así entendido, no es simplemente aquello que traduce la lucha o los sistemas de dominación, sino aquello por lo que, y por medio de lo cual se lucha, aquel poder del que alguno quiere adueñarse. Estas luchas y tensiones permean las practicas discursivas y la forma en como significamos las distintas formas de referirnos a los temas y las negociaciones que se dan al momento de construir argumentaciones.

Habermas desarrolla una comprensión de la razón pública del discurso enraizada en un ideal de comunicación y ética. Señalando que el discurso forma parte del entendimiento de religioso" o "lo político". Intervienen diversos componentes en un discurso y los significados producidos por el hablante/escritor los sujetos a fin de lograr consensos. Sin embargo, rompe con la lógica desordenada y conflictiva.

Esta vertiente del análisis del discurso permite acercarse a lo que piensan los actores públicos a partir de lo que ellos mismos dicen en torno a un asunto central sobre el cual se quiere profundizar. En este sentido, es relevante tomar en cuenta qué se propone como conflictivo en la arena pública, qué valores se proponen y se sienten comunes entre los bandos polarizados y cómo interpretan en clave colectiva lo que es importante a su entorno (Pardo, 2007).

\section{Perspectiva de análisis: el debate público}

La pretensión original fue la recuperación y el análisis del universo total de 80 notas informativas periodísticas sobre temas de interés público. Las notas se recuperaron los diarios de circulación local y el criterio para la selección siguió la directriz de los temas de agenda política local que fueran más representativos. Se buscó fuera lo más diversa posible. En el siguiente cuadro (cuadro 1) se muestra cómo es su distribución.

Cuadro 1. CORPUS DE DOCUMENTOS Y NOTAS INFORMATIVAS

\begin{tabular}{|c|c|c|c|c|c|c|c|}
\hline Actores & $\begin{array}{c}\text { Diario de } \\
\text { Querétaro }\end{array}$ & Noticias & AM & $\begin{array}{c}\text { Plaza de } \\
\text { Armas }\end{array}$ & $\begin{array}{c}\text { Documentos } \\
\text { Oficiales/Boletín de } \\
\text { Prensa }\end{array}$ & $\begin{array}{c}\text { Documentos } \\
\text { Propios }\end{array}$ & TOTAL \\
\hline $\begin{array}{c}\text { Gobierno del } \\
\text { estado }\end{array}$ & 10 & 7 & 5 & 3 & 10 & 3 & 38 \\
\hline $\begin{array}{c}\text { Gobierno } \\
\text { municipal }\end{array}$ & 15 & 6 & 5 & 3 & 5 & 0 & 34 \\
\hline $\begin{array}{c}\text { Asociaciones } \\
\text { civiles (*) }\end{array}$ & 0 & 0 & 0 & 0 & 0 & 3 & 3 \\
\hline Académicos (*) & 0 & 0 & 0 & 0 & 0 & 3 & 0 \\
\hline $\begin{array}{c}\text { Asociaciones } \\
\text { Empresariales }\end{array}$ & 2 & 0 & 0 & 0 & 15 & 9 & 80 \\
\hline
\end{tabular}

(*) Aparecen en notas del periódico La Jornada y del Semanario Libertad de Palabra. Pero no en diarios de circulación local.

$$
\text { Fuente: Elaboración Propia }
$$

Una primera lectura, permite extraer datos como la cantidad de notas exhibidas en cada uno de los diarios, así como la frecuencia con la que este tema aparece visible y en qué condiciones. Así mismo, la relevancia que se asigna al tema, dependiendo de su ubicación y extensión en el diario para, eventualmente, rescatar las tendencias en la polifonía que se visibiliza en los medios.

Una segunda fase del análisis pone en juego estos datos con el propósito de reconstruir las representaciones discursivas puestas en circulación en la prensa local. La recuperación del tejido presentado en los diarios permitirá armar la matriz que las articula como muestra de la calidad del diálogo público en la ciudad. 
Este acercamiento permite enfocar, las voces de los actores por lo que se pone en juego en la arena comunicativa compartida que proveen los medios. Así, al entender quiénes aparecen y con qué argumentos, será posible la investigación de la construcción del diálogo público lo que, eventualmente puede dar cuenta de la cualidad del debate que sobre temas de interés se tienen en los medios de Querétaro.

Con este propósito y a partir de las notas periodísticas se elaboró el mapa de actores sociales y se procedió al análisis de los argumentos del diálogo. La intención fue encontrar la relación entre los debates generados, la inclusión de los actores y las posturas que van generando en torno al tema a partir de su posición social, la visibilidad y la importancia que generan para la prensa. Así, es posible observar a calidad de los canales de comunicación en donde los actores sociales pueden rescatar tanto como aportar a asuntos que, como el agua, son preocupación compartida.

Para establecer una interpretación se realizó un ejercicio final como articulación entre la configuración de la esfera pública y los resultados de la última Encuesta Nacional de Cultura Política y Prácticas Ciudadanas que aplicó el INEGI en 2012. Esta encuesta tiene por objetivo diagnosticar los rasgos de la cultura política y de las prácticas ciudadanas predominantes entre los mexicanos e identificar los factores que los explican y los condicionan, con la finalidad de mejorar el impacto de las acciones que impulse el Ejecutivo Federal con el fin de promover transformaciones culturales que den sustento a la gobernabilidad democrática en México (INEGI, 2012).

Los datos de la encuesta arrojan elementos clave para entender el comportamiento político y de participación de la sociedad en Querétaro en lo particular y en México. Con ello se puede dar cuenta de las condiciones de visibilidad e invisibilidad de actores sociales. Se establecieron parámetros para analizar la interacción de los actores sociales en los espacios de debate. Y la configuración de la esfera pública cuyo carácter incluyente y de participación está diluido por los actores sociales pertenecientes a la oligarquía.

Para el estudio, fue relevante reconocer ambos actores y la presencia que estos tuvieron en el debate. Si se parte de la idea de que el debate, y por ello el discurso a través de sus argumentaciones, es un elemento que constitutivo de la esfera pública fue preciso situar quiénes son los actores que tienen visibilidad en ella y quiénes resultan marginados. Es necesario destacar que no necesariamente los actores que estuvieron en contra y que refirieron sus argumentaciones en ese sentido son invisibilizados, algunos tienen presencia en el debate; sin embargo, existen otros actores que no son visibles y que no forman parte de las discusiones que prevalecen en la esfera pública.

Es importante tener en cuenta que el análisis propuesto buscó, a partir de los discursos, conocer la reproducción de prácticas autoritarias en la esfera pública, ancladas a la cultura política en Querétaro a pesar de la democratización a nivel normativo.

\section{Diseño de análisis y resultados}

En la estrategia que se construyó para el análisis I se realizó el cruce de las relaciones entre las variables para buscar sus relaciones y, en su debido caso, las dependencias. Se trata de establecer los patrones en los que los actores o los argumentos se presentan en su ubicación y el tratamiento que se le otorga.

En un primer momento, se recogen las relaciones entre las categorías de los actores: el tipo de interacción, la visibilidad y la esfera en la que se desenvuelven. El propósito es el establecimiento de una tipología de actores y puntos de vista que son puestos en juego en el debate. 
En segundo lugar, se reúnen los argumentos que se consideran como indicios de las orientaciones que toma el diálogo, de este caso, en la prensa de la ciudad. Las consideraciones articulan las relaciones discursivas entre los actores en la esfera pública. Con ellas, los actores en la sociedad construyen la representación del entorno y lo relaciona con su práctica social y política.

Cada una de las variables y subcategorías analizadas y correlacionadas arrojan elementos para indagar sobre los niveles de visibilidad, representación, reproducción y legitimación de las formas simbólicas expresadas por los autores y que son puestas a disposición de la representación colectiva que se construye a través de la prensa.

Finalmente, se expone el aspecto formal de la nota que clasifica el periódico de publicación, la ubicación de la nota sección y plana, así como la fecha. Estos elementos también aparecen como relevantes puesto que definen la actitud del medio en la visibilización del argumento o del actor. La cronología, por su parte, ilustra si el argumento es original o reproducido para dilucidar si se expusieron nuevos o se siguió justificando la obra y su desarrollo de forma consistente.

Se halló que la esfera desde la que se comunica está vinculado a la institución con la que se le asocia y la colocación que se hace del actor como representante de ésta que, a su vez, determina cómo se presenta el actor. Todo esto tiene una relación muy fuerte con el periódico y la plana donde se expone la nota. Otros factores que colaboran que influyen en dónde se sitúa la nota son el nombre del protagonista y, por lo tanto, el tipo de actividad desde donde los argumentos obtienen su legitimación.

De acuerdo con las conexiones anteriores, la mayor visibilidad en medios fue obtenida por la clase política, ya que 74 por ciento de los actores en las notas reportadas pertenecen a esta esfera del poder público. En segundo lugar, se encuentra la esfera social (16 por ciento) y finalmente, la esfera económica (diez por ciento).

Gráfica 1. RELACIÓN ESFERA-ASOCIACIÓN

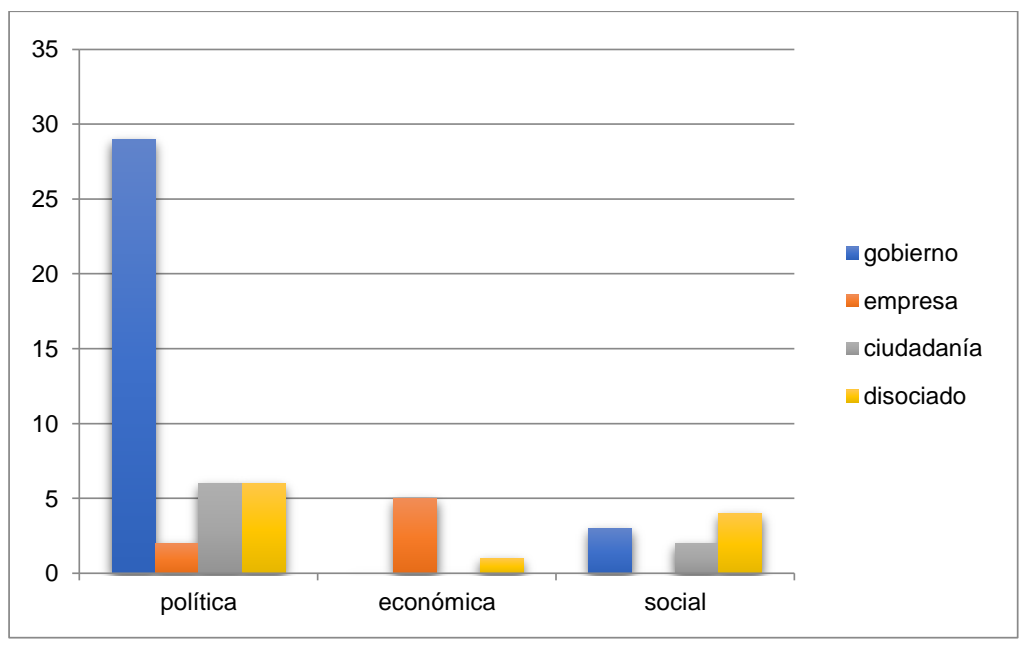

Fuente: Elaboración Propia

La Gráfica 1 muestra un claro referente discursivo o un interlocutor principal en el debate, claramente ubicado en la esfera de la política que reduce y confunde el papel real del sector privado en el caso y minimiza la voz de la esfera social. De todos los actores posibles, la obra se asocia al gobierno estatal en 59 por ciento de las notas seleccionadas mientras que la esfera social no llega a cinco por ciento. Desde la Esfera Política se construye el sentido de legitimación del proyecto al asociarlo en diez por ciento de los casos a la ciudadanía. 
La prensa es un mecanismo que visibiliza o excluye actores. De ahí que la relación entre el periódico y la visibilidad del actor (Gráfica 2) sea estadísticamente comprobable. Estos espacios, otorgados según la agenda de cada medio, promueven o invisibilizan discursos.

Gráfica 2. VISIBILIDAD DEL ACTOR, TIPO DE DISCURSO Y SU PROYECCIÓN EN PRENSA

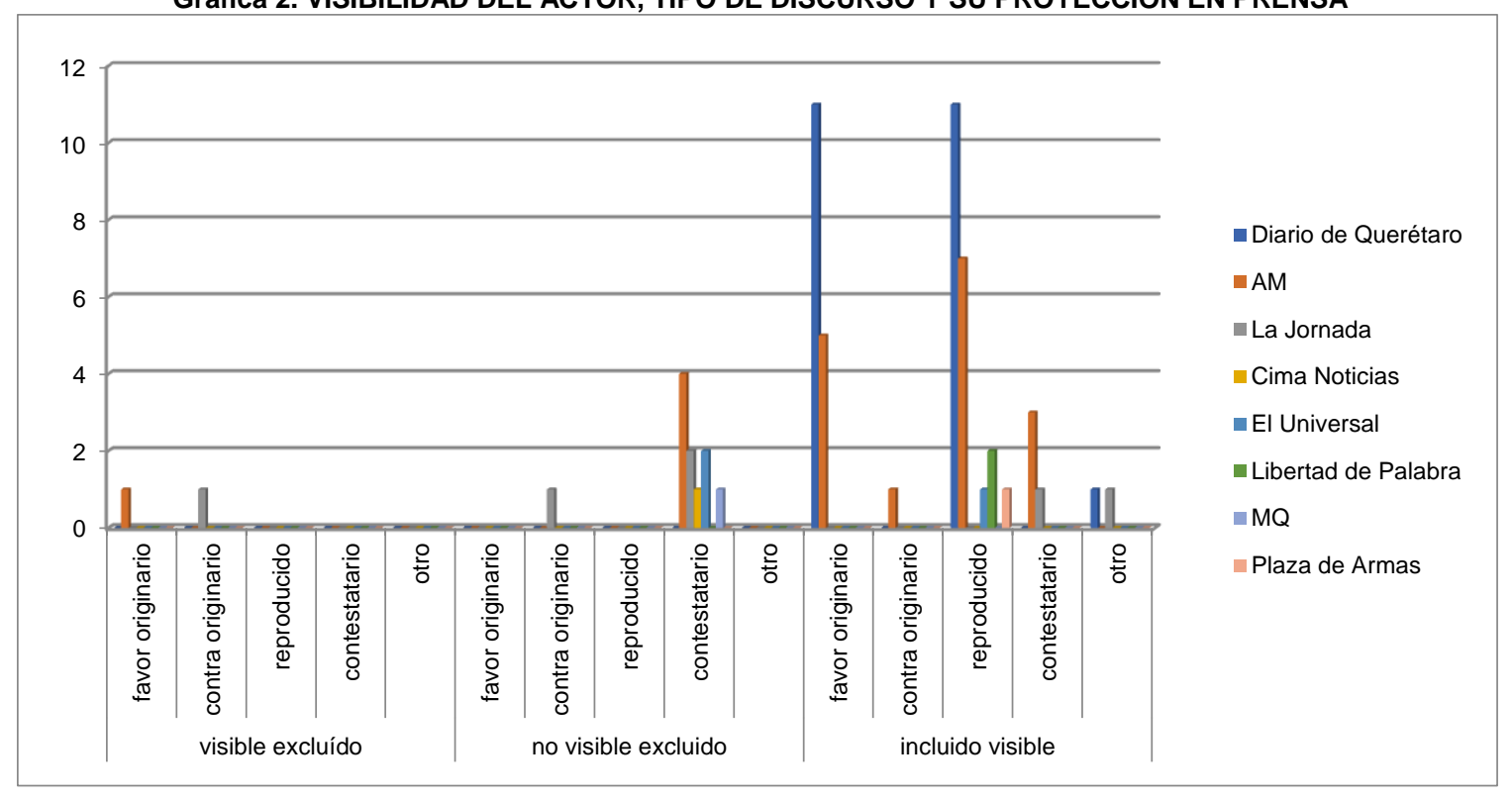

Fuente: Elaboración Propia

El medio predilecto para la proyección de la información oficial es Diario de Querétaro, cuyas notas provenían principalmente de la esfera política (34 por ciento, tal y como se muestra en la Gráfica 3.

Plaza de Armas, al contrario, en los últimos años ha tenido un nulo acceso a las puertas de Palacio de Gobierno, aunque 29 por ciento de su información proviniera de actores de la esfera política. Pese a ello, emitía comunicaciones de actores que son opositoras a la actual administración gubernamental

El caso de La Jornada es diferente. Por la claridad en su línea editorial, declaradamente de izquierdas, fue espacio de visibilidad de discursos contestatarios realzando las voces excluidas del debate y dando espacio a los discursos provenientes de las tres arenas que interactúan en la esfera pública: mercado, sociedad civil y Estado. Lo mismo ocurrió en espacios de prensa más reducidos como $M Q$ o La Cima, donde aparecían en exclusiva discursos contestatarios emitidos por actores excluidos no visibles, pertenecientes a la esfera social. 
Gráfica 3. ESFERA DEL ACTOR EN EL PERIÓDICO

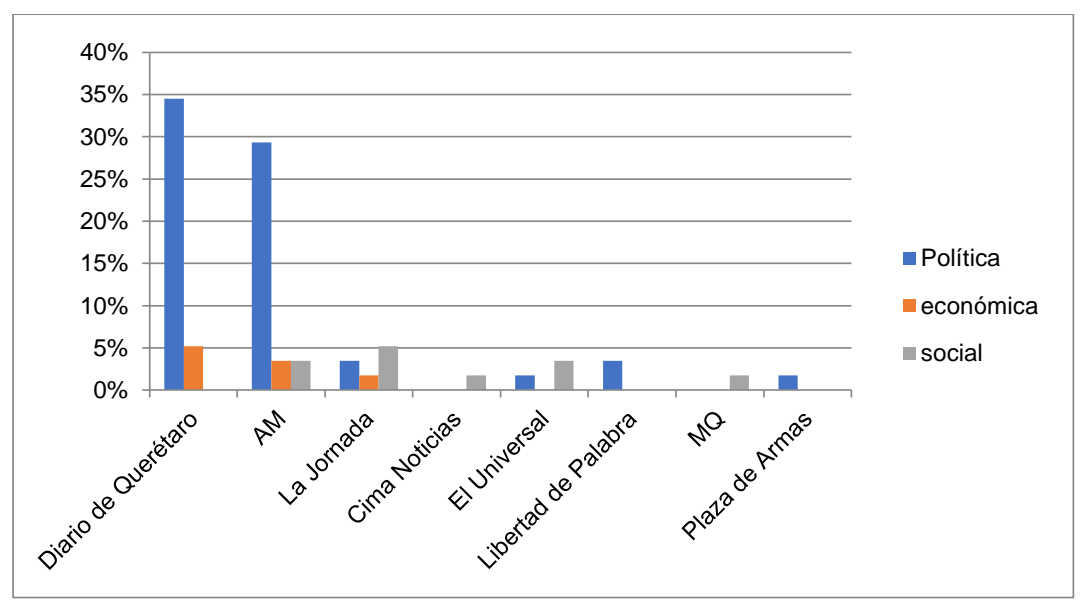

Fuente: Elaboración Propia

En forma contraria, la prensa local se concentra en promover el discurso originario favorable o su reproducción acrítica fomentando los actores visibles e incluidos en el debate de la esfera pública.

La función de los actores en sus esferas respectivas fue lo esperado en cuanto a la producción y reproducción de argumentos. Lo que muestra el tejido previamente descrito es cómo se produce y reproduce la información, quién tiene espacios y quién no, quién los da y quién los niega, es decir, en qué condiciones aparecen los actores. Es posible observar cómo se construyen discursos desde la esfera política, con actores visibles e incluidos en esta discusión, que gracias a la prensa local obtienen mayor notoriedad y cuyo flujo informativo también es reproducido por la prensa más pequeña.

Los discursos contestatarios o que desde un origen estaban en contra del proyecto provienen principalmente de la esfera social y tuvieron que buscar sus propios espacios de visibilidad fuera de los medios dominantes en Querétaro o en la sección de Estados de la prensa nacional. Los actores pertenecientes a la esfera económica aparecen de forma aislada, reproduciendo mecánicamente las frases creadas desde los actores pertenecientes a la esfera política

Una de las estrategias usuales para diluir la responsabilidad en el discurso es la colectivización de individuos. Hablar en nombre de un grupo congregado a partir de una cierta característica (los queretanos, por ejemplo) es el recurso más empleado por actores en las tres esferas (Gráfica 4). Es el único empleado en el discurso de las empresas, lo que vuelve a probar la idea de su aislamiento y su búsqueda de opacidad diluyendo su participación tras los actores políticos.

\section{Gráfica 4. REPRESENTACIÓN DE LOS ACTORES EN LAS ESFERAS}

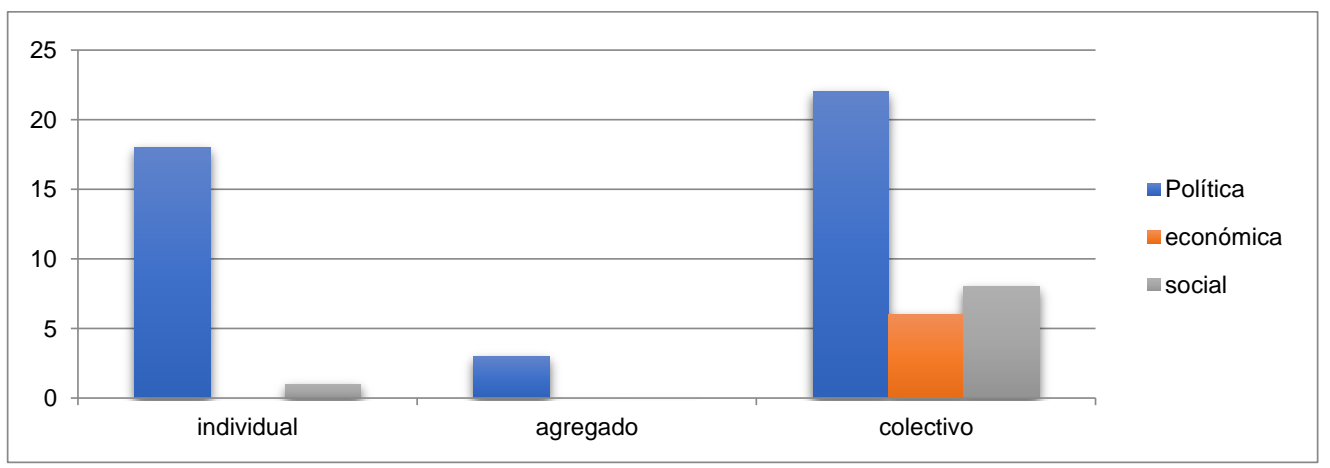

Fuente: Elaboración Propia

Pangea. Revista de la Red Académica Iberoamericana de Comunicación ISSN: $2172-3168$ | https://revistapangea.org Vol.11, núm. 1 (2020) | Páginas: 61-78 | DOI: xxxxxx 
La agregación, estrategia discursiva que consiste en emplear números o estadísticas para hablar de personas, es empleada únicamente por los actores pertenecientes a la esfera política. Un ejemplo es la denominación de "beneficiados", utilizada frecuentemente como legitimador. Es posible inferir que hubo dos usos de esta estrategia discursiva. Por un lado, en 63 por ciento de los casos eso se da entre actores visibles o que buscaron mayor visibilidad

En el análisis de las esferas, los actores retoman referentes para la construcción de sus discursos y estos mismos han resultado ser una de las variables más relevantes en la configuración de la esfera pública. Como es posible entrever, se ha probado que están relacionados significativamente con la mayoría de las variables construidas para la interpretación de la argumentación discursiva de los actores.

Gráfica 5. ESTRATEGIAS DE LEGITIMACIÓN SEGÚN ESFERAS DE INTERVENCIÓN DEL ACTOR

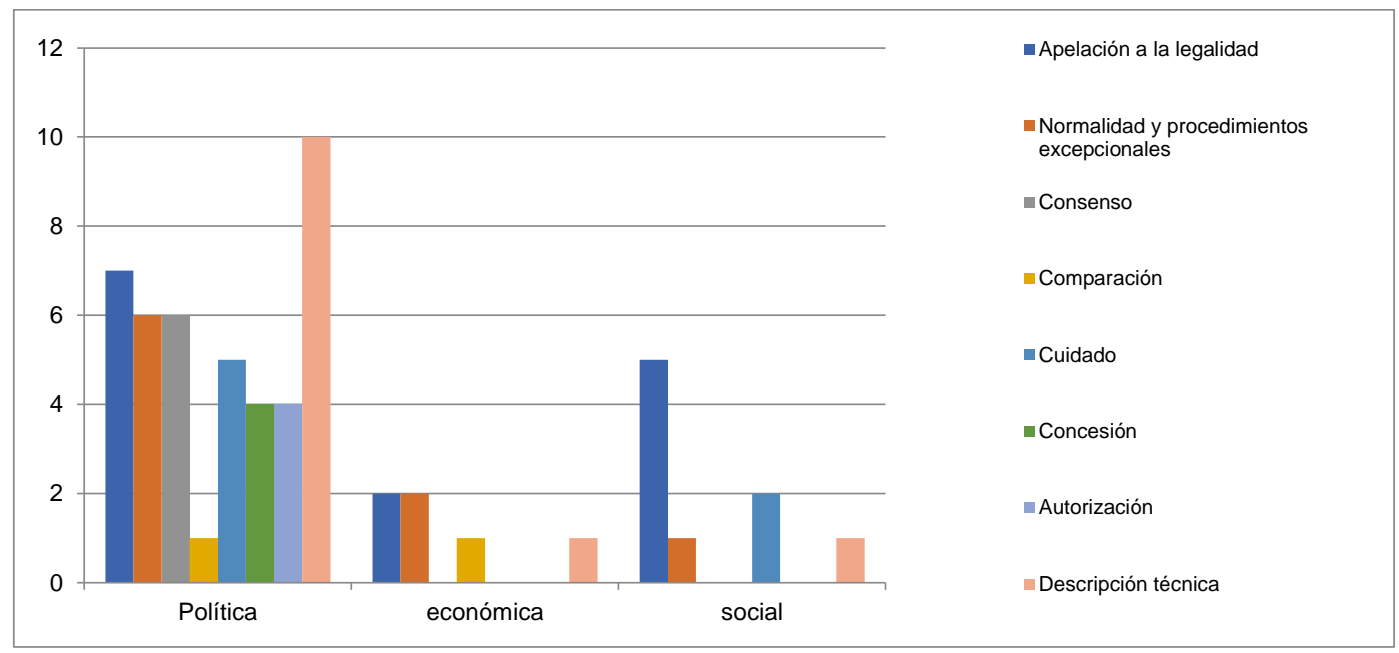

Fuente: Elaboración Propia

Las estrategias de legitimación revelan una homogeneidad en todos los casos. Cualquier actor, desde cualquier esfera y en cualquier medio, puede argumentar cualquiera de las ocho estrategias establecidas por Poblete (2011). La preferida entre los actores del debate público en torno a la apelación a la legalidad (24 por ciento). Con esta estrategia se aísla el asunto para encomendarlo a una instancia que trasciende al actor como referencia de autoridad. Por otro lado, el actor que remite a esta abstracción se apropia o se atribuye la legitimidad de estar del lado de la ley. Al mismo tiempo, deja sobreentendido que aquel que no esté del lado del discurso, es decir, de la ley, está en contra no sólo de la autoridad sino de la ciudadanía que delegó su poder en este representante electo.

La segunda estrategia de legitimación más empleada fue apelar a las descripciones técnicas (21 por ciento). Estas estrategias tratan de explicitar los detalles estadísticos para volverlos relevantes. El principal aspecto de esta estrategia discursiva es la permanente mención a la inversión monetaria, y aunque ello sirva para legitimar el proyecto se puede usar, después, para cuestionarlo, debido a un gasto público que excedió de lejos el presupuesto inicial.

Un segundo foco de apelación técnica que llama la atención es el argumento de la viabilidad. Desde el principio, los grupos sociales con este discurso (contra) argumentan opciones diversas que no perjudican las finanzas públicas.

Tanto la legalidad como el medio ambiente son referencias inaprehensibles, que trascienden a los actores y por ello conceden autoridad a quienes los usan. Otra de estas estrategias clásicas es 
apelar al consenso. Es la clase política la que usa (y abusa) del concepto en las notas recuperadas sobre el asunto. La referencia visible de esta práctica discursiva.

Se utiliza un lenguaje basado en identificar retos y buscar un consenso con instituciones públicas, privadas y de la sociedad civil.

\section{Conclusión}

En México ha habido una paulatina apertura en los medios. De hecho, en Querétaro la prensa creció en el siglo XXI pasando de dos a seis diarios. Lo que en cierto momento pudo significar más espacios para otros actores sociales terminó bajo el mismo esquema de acuerdos bajo el agua. Salvo el caso de $A M$ y recientemente Plaza de Armas, quien por las mismas prácticas y acuerdos han tenido ciertos roces con los poderes político y económico, el resto de los medios escritos se acomodó a la pauta de reproducir las prácticas de producción informativa y de reproducción discursiva.

El discurso de la prensa sigue, en buena medida, supeditado a negociaciones de poder, lo que se refleja en los textos periodísticos. De acuerdo con lo establecido en el marco conceptual, en la esfera pública tiene lugar el debate de los asuntos de interés colectivo. Al analizar este esquema y asociarlo a los procesos de democratización, se asume que los distintos actores discuten los asuntos públicos y logran consensos que mejoran la consolidación y calidad de los regímenes democráticos. La esfera pública representa, en este sentido, el espacio en donde los actores se disputan la visibilidad y la influencia en los procesos de constitución de la agenda pública y de las decisiones colectivas. En la esfera pública se manifiesta, pues, la fuerza o debilidad de los actores y la capacidad de los ciudadanos para interactuar y participar en la definición de los asuntos públicos.

Con la alternancia política en México, se presume que hubo una serie de cambios en las normas y en las prácticas colectivas, ingrediente que teóricamente define el proceso de democratización. Sin embargo, reforma y apertura no han sido garantía suficiente para producir un cambio en la cultura política de ciertas regiones del país. La evidencia muestra que esta apertura no ha permitido el acceso a la esfera pública a sectores silenciados de la población. Es claro entonces que sin el acceso de más agentes no se puede configurar una esfera pública realmente democrática. Analizar a los sujetos en sus prácticas de significación y ante el concepto de democracia en la esfera pública es algo necesario.

En el caso de Querétaro, entendiendo que el proceso de democratización y configuración de la esfera pública no son la misma cosa, cabe decir que el acceso a la opinión pública continúa limitada a cierto sector de actores. Heredera de una cultura autoritaria, la esfera pública de Querétaro ha tendido siempre a mantener cierta potestad en cuanto a los actores que pueden tener acceso a ella.

La práctica periodística señala que ahí radica lo noticioso pero la cultura política del Estado sugiere lo contrario. Para la prensa local, esos reclamos o problemas no tenían por qué ser visibilizados en la esfera pública. En todos los casos se aceptó qué existía algún tipo de conflicto (tres de ellos relacionados con el tema de la calidad de vida) pero más que dar explicaciones 0 contextualizar el tema, se trató de negar la responsabilidad del Estado y el mercado.

La sociedad queretana no se articula en sus actores políticos. Este factor explica la falta de compromiso de los funcionarios electos en sus discursos, acciones o toma de decisiones. La política tiende a alejarse de los ciudadanos para servir a los intereses especiales, razón por la cual el mismo término adopta un sentido negativo. La práctica política de la sociedad queretana se limita exclusivamente al ejercicio del voto; pero acorde a los datos de la encuesta nacional de cultura política esto no significa una valoración positiva de la democracia o de la política. En 
realidad, los encuestados consideran de poco interés y demasiado complejo el arte de la política. Manifiestan en mayor proporción una idea diferente a lo que podría pensarse respecto a una sociedad en proceso de democratización. Los contenidos seleccionados por los medios privados permiten que las audiencias se apropien de los discursos y las formas simbólicas relacionadas con política que aparecen en los informativos.

Si bien las personas obtienen información sobre asuntos de interés común en los medios electrónicos, la escasa discusión que de ella hace, se realiza en espacios privados, principalmente en familia (INEGI, 2012). La vinculación de los encuestados con la política es muy lejana porque la consideran compleja. Incluso predomina una valoración negativa por las razones señaladas. Al fin de este viaje hacia la utopía democrática, muchos descubren que las preocupaciones reales no son visibles en la esfera mediática. Los espacios de interacción colectiva entre el Estado, el mercado y la sociedad civil que deberían darse en la esfera pública dominada por los medios de comunicación no llegan a concretarse.

La discusión social de los asuntos públicos se lleva a cabo en el ámbito de lo privado apuntando a una de las causas del poco compromiso social de los actores políticos y el desdén de la sociedad civil que muestran los medios locales. No se toman en cuenta opiniones o perspectivas diversas porque sus fuentes de ingreso, su red de sociabilidad y su público aceptan el status quo predominante en Querétaro.

Con estos datos se pueden inferir ciertas aproximaciones a la configuración de la esfera pública. La política no solo implica un proceso netamente electoral, sino una verdadera participación social que se debe efectuar día a día con las decisiones. Lo que muestra este análisis y la misma esfera pública de Querétaro es que aún queda un largo camino para articular en prácticas reales lo que el diseño institucional muestra. La articulación entre los diversos sectores sociales con la finalidad de integrar múltiples voces al debate público sigue pendiente en Querétaro.

\section{Referencias bibliográficas}

Acosta, R., Paláu, S y Larrosa, J. (2014). Decisiones públicas sin diálogo público: análisis de los argumentos sobre el caso de la vía express vertidos en la prensa de Guadalajara. Comunicación y Sociedad, 21.

Almond, G. y Verba, S. (2001). La cultura política, in: Battle, A. (Ed.), Diez Textos Básicos de Ciencia Política. Ariel, Madrid, pp. 171-201.

Andrade, P. (2009). La democracia en el espacio público mediático. Global Media Journal, 6, 12, pp. 91-100. Instituto Tecnológico y de Estudios Superiores de Monterrey Monterrey, México.

Avritzer, L., (2002). Democracy and the public Space in Latin America New Jersey: Princeton University Press.

Avritzer, L. y Sousa, Boaventura de (2003). Para ampliar el canon democrático Revista Crítica de Ciencias Sociales.

Elías, N., (1999). Teoría del símbolo: un ensayo de antropología cultural. Barcelona: Península

Espino, G., (2003). El Crack del 97. Querétaro: UAQ-IEQ.

Espinoza, V., (2010). Redes de poder y sociabilidad en la élite política chilena. Los parlamentarios Polis, Revista de la Universidad Bolivariana. Vol. 9, n² 26, pp. 251-286.

González, C., (2013) "Una interpretación sobre la construcción del espacio urbano: Querétaro, de la tradición a la modernidad y de la modernidad a la globalización", en Bassols Ricardez, Mario, Procesos de construcción de espacios urbanos en ciudades mexicanas, siglo XIX y XX. 
Gutiérrez Cham, G. (2003). Introducción a la noción de discurso. México: Universidad de Guadalajara.

Habermas, J. (1962/1981). Historia y crítica de la opinión pública. La transformación estructural de la vida pública México: Gustavo Gili

INEGI (2012) "Encuesta Nacional de Cultura Política y Prácticas Ciudadanas". Recuperado de www.inegi.org,mx/programas/encup/2012/

Morales, M. (1998). La nueva generación de políticos queretanos. UAQ, Querétaro.

Nieto, J., (2000). Del Hacendado al Empresario México: UAQ-CUMDES, México.

Pardo, N. (2007). "Cómo hacer análisis crítico del discurso. Una perspectiva latinoamericana", Frasis, Santiago de Chile

Poblete, C. (2011). "Estrategias de legitimación del discurso de los diputados en la Acusación Constitucional en contra de la Ministra de Educación de Chile", Signos, 44 (76), pp. 168-182, DOI: $10.4067 /$ S0718-09342011000200005

Subirats, E. (2010). De la grandeza de la lengua española, seguido de otros dilemas. Estudios de lingüística del español. Estudios de Lingüística de Español (ELiEs) 31. [Recuperado 10 de enero de 2020] Disponible en línea: http://ddd.uab.cat/pub/elies/elies_a2010v31/index.html.2

Thompson, J.B. (1998). Los media y la modernidad: una teoría de los medios de comunicación. Barcelona: Paidós.

Thompson, J.B. (1993). Ideología y cultura moderna. Teoría crítica social en la era de la comunicación de masas (2a ed.). México, D.F.: Universidad Autónoma Metropolitana, Unidad Xochimilco, División de Ciencias Sociales y Humanidades,

Van Dijk, T. (2006). Discurso y manipulación: Discusión teórica y algunas aplicaciones. Signos, 39 (60), pp. 49-74.

\section{NOTAS}

\footnotetext{
${ }^{\text {i }}$ Encuesta Nacional de Cultura Política y Prácticas Ciudadanas. INEGI 2012.

ii La democratización, es entendida como un proceso que, en sentido normativo, permite el establecimiento de regímenes institucionales que construyen marcos de actuación legal apegados a elecciones concurrentes e igualdad en el sistema gubernamental. Así mismo supone derecho de acceso a información, rendición de cuentas y participación social en la toma de decisiones.

iii Articulo estos dos conceptos porque más adelante, y acorde al planteamiento de Thompson (1993) me centro en la producción y reproducción de formas simbólicas en la esfera pública queretana. La cultura política es representada por sistemas de valores, representaciones simbólicas e imaginarios colectivos, que se ponen de manifiesto en los discursos y prácticas observados en la esfera pública y forman parte del material empírico a analizar.

${ }^{\text {iv }}$ En datos COESPO, la población de la capital del estado en 2019 cuenta con 960, 000 habitantes. A los que habría que sumar, en la actividad económica diaria, los habitantes de los municipios conurbados: Corregidora con 200,000 habitantes y El Marques con 160,000. Información recuperada en: https://gobqro.gob.mx/coespo/indicadores-pormunicipio/
} 